\title{
Synthesis of novel oxide layers on titanium by combination of sputter deposition and micro-arc oxidation techniques
}

\author{
Myat NYAN ${ }^{1}$, Yusuke TSUTSUMI², Kei OYA³ ${ }^{3}$, Hisashi DOI², Naoyuki NOMURA², Shohei KASUGAI ${ }^{1}$ \\ and Takao HANAWA ${ }^{2,4}$
}

\begin{abstract}
${ }^{1}$ Graduate School of Medical and Dental Sciences, Tokyo Medical and Dental University, 1-5-45 Yushima, Bunkyo-ku, Tokyo 113-8510, Japan ${ }^{2}$ Institute of Biomaterials and Bioengineering, Tokyo Medical and Dental University, 2-3-10 Kanda-Surugadai, Chiyoda-ku, Tokyo 101-0062, Japan ${ }^{3}$ Research Institute of Science and Technology, Kogakuin University, 2665-1 Nakano, Hachioji, Tokyo 192-0015, Japan ${ }^{4}$ Department of Materials Engineering, Graduate School of Engineering, The University of Tokyo, 7-3-1 Hongo, Bunkyo-ku, Tokyo 113-8656, Japan Corresponding author, Yusuke TSUTSUMI; E-mail: tsutsumi.met@tmd.ac.jp
\end{abstract}

\begin{abstract}
A novel coating technique of thin ceramic layer resembling teeth color on titanium (Ti) surface was developed by combination of sputter deposition of metal zirconium (Zr) and subsequent micro-arc oxidation (MAO) treatment. The oxide layer grown by MAO treatment had a porous structure with a thickness of approximately 6 micrometers and was mainly composed of zirconium dioxide $\left(\mathrm{ZrO}_{2}\right)$ with both tetragonal and monoclinic crystal structures. The surface of the specimen was hardened by this technique, and the hardness of the specimen was significantly larger than that of untreated Ti and MAO-treated Ti without Zr layer. The bonding strength test revealed that fracture occurred inside the oxide layer, indicating that adhesion between the oxide layer and the Ti substrate was sufficiently strong. From these results, this technique has an advantage for the development of novel dental materials with excellent mechanical and aesthetic properties.
\end{abstract}

Keywords: Titanium, Zirconium oxide, Sputter deposition, Micro-arc oxidation, Aesthetic

\section{INTRODUCTION}

Aesthetic considerations have become major in modern dental implant treatment. Implant restorations in the anterior esthetic zone present significant challenges in both the surgical and prosthetic phases. Many implant systems apply transmucosal abutments to retain prosthetic restorations. In many cases, the metal color of the abutment is transmitted through the peri-implant tissues. The appearance of a metal halo at the margin of the gingiva or exposure of the metal abutment collar due to gingival recession is one of the most common causes of aesthetic failure of anterior implants. Recently, new zirconia ceramic abutments have been introduced to improve aesthetic results. Zirconia is a kind of oxides of zirconium ( $\mathrm{Zr}$ ), and crystalline dioxide of zirconium $\left(\mathrm{ZrO}_{2}\right)$ is practically used in dental field as zirconia ceramics. $\mathrm{ZrO}_{2}$ is very hard, white in color, and matches the color of natural teeth ${ }^{1)}$. Moreover, $\mathrm{ZrO}_{2}$ has been shown to be bioinert, biosafe, and corrosion-resistant.

One alternative method for the application of this biologically and aesthetically favorable zirconia is to deposit thin ceramic layers on a titanium (Ti) surface. Various methods for the deposition of $\mathrm{ZrO}_{2}$ thin layers have been applied, such as sputter deposition, electron beam deposition ${ }^{2)}$, plasma ${ }^{3)}$ and ion beam ${ }^{4)}$ deposition, sol-gel processing ${ }^{5}$, and chemical vapor deposition. Among them, the sputter deposition technique has been widely used to achieve metallic oxides with homogeneity, good uniformity, and low deposition temperature ${ }^{6,77}$. The elementary event in sputter deposition is an atomic collision cascade. The incident ion knocks atoms in the target from their equilibrium positions, thus causing these atoms to move in the material and to undergo further collision, finally causing the ejection of atoms through the target surface ${ }^{8}$. However, it has been reported that a thin layer coating of $\mathrm{ZrO}_{2}$ applied by sputter deposition does not appear white, although the bulk $\mathrm{ZrO}_{2}$ material has a white appearance. The structure and properties of thin film materials are significantly different from those of the same materials in bulk ${ }^{6,9)}$.

Our strategy is to coat a thin layer of metal $\mathrm{Zr}$ on a Ti surface from a metal target by sputter deposition followed by oxidation of the resultant surface. Micro-arc oxidation (MAO), also called plasma electrolytic oxidation or anodic spark oxidation, is a useful anodic oxidation technique to deposit ceramic coatings on the surface of valve metals, such as $\mathrm{Al}, \mathrm{Ti}, \mathrm{Zr}$, and their alloys ${ }^{10-17)}$. MAO processes are typically characterized by the phenomenon of electrical discharge on the anode in the aqueous solution. Using the MAO technique, high-quality coatings with high micro-hardness, adhesion strength, and wear resistance can be synthesized on metals ${ }^{18)}$.

The objective of this study was to develop an implant abutment surface by achieving thin $\mathrm{ZrO}_{2}$ layers on the Ti surface with aesthetically favorable color, high mechanical properties, and strong bonding strength. The present work focused on the preparation of $\mathrm{ZrO}_{2}$ layers by micro-arc oxidation of a sputter-deposited $\mathrm{Zr}$ thin film on a Ti substrate. Characterization of the structure, phase components, color, hardness, and bonding strength of the oxide layers was performed to evaluate the application for the development of novel dental implants. 


\section{MATERIALS AND METHODS}

\section{Ti substrate and sputter deposition of $\mathrm{Zr}$}

Commercially pure Ti (grade 2) (Rare Metallic, Tokyo, Japan) disks were used as the substrate material. The disk was $10 \mathrm{~mm}$ in diameter and $1.5 \mathrm{~mm}$ in thickness. Prior to the process, the surfaces of the disks were mechanically polished with $\mathrm{SiC}$ abrasive paper up to \#800 grit and cleaned in acetone and ethanol with ultrasonic cleaner.

Pure $\mathrm{Zr}$ was sputter-deposited on Ti. A pure $\mathrm{Zr}$ (99.2\%) (Kojundo Chemical Laboratory, Saitama, Japan) was used as a target in a DC magnetron sputter deposition system (DLC7527, Nanotec Corporation, Chiba, Japan). Before sputter deposition, the target was pre-sputtered to remove the contaminant layer from the erosion track. The deposition parameters are shown in Table 1. The deposition time was determined to achieve a $\mathrm{Zr}$ layer with $5 \mu \mathrm{m}$ in thickness according to prior calibration measurement of the deposition condition.

\section{Micro-arc oxidation of sputtered Zr film}

A high-voltage DC power supply (PL-650-0.1, Matsusada Precision, Shiga, Japan) was used for the MAO treatment. The specimen was used as an anode, while a stainless steel plate was used as a cathode. The specimen was mounted in a special holder consisting of polytetrafluoroethylene (PTFE) so that only a part of the upper surface was exposed to the electrolyte $(8 \mathrm{~mm}$ in diameter). Details of the working electrode are described elsewhere ${ }^{19)}$. Various electrolyte solutions with different concentrations of calcium glycerophosphate and magnesium acetate (Wako Pure Chemical Industries, Osaka, Japan) were prepared (Table 2). The initial stage of the MAO treatment was carried out with a constant- current density of $239 \mathrm{Am}^{-2}$, while the maximum voltage was limited at $480 \mathrm{~V}$. The treatment time was changed from 10 to $40 \mathrm{~min}$ until the surface of the specimen appeared to be uniformly oxidized. The specimens were then washed with distilled water and dried with a stream of air at room temperature. For comparison, Ti disks without a $\mathrm{Zr}$ deposition layer were also MAO-treated in the same manner.

\section{Surface characterization}

The surface morphology, elemental composition, and crystal structure of the resultant oxide layers were analyzed using scanning electron microscopy with energy-dispersive X-ray spectroscopy (SEM/EDS, S-3400N, Hitachi High-Technologies, Tokyo, Japan) and an X-ray diffractometer (XRD, PW-1710, Philips, Almelo, Netherlands).

The Vickers hardness of the oxide layer was measured using a hardness tester (HMV Micro Hardness Tester, Shimadzu, Kyoto, Japan) with an indentation load of $0.98 \mathrm{~N}$ for $15 \mathrm{~s}$. The measurement was repeated five times at different areas of the each specimen.

The bonding strengths between the oxide layer and the substrate were evaluated using an adhesion-tension test with an autograph (AG-2000B, Shimadzu, Kyoto, Japan). Both sides of the specimens were attached to the bottom of cylindrical steel rods with a 3-mm diameter using an adhesive reagent (Extra Glue, Konishi, Osaka, Japan). After the rods were assembled in the machine, tensile load was applied to the specimen with a constant speed of $0.05 \mathrm{~mm} \mathrm{~min}^{-1}$ until detachment occurred. The measurement was repeated four times at different areas of the each specimen. The detached surfaces were observed with SEM to evaluate where the failure occurred.

Table 1 The sputter deposition parameters of $\mathrm{Zr}$ on a Ti substrate

\begin{tabular}{lccc}
\hline DC power $(\mathrm{W})$ & Ar flow rate $(\mathrm{sccm})$ & Distance $(\mathrm{mm})$ & Time $(\mathrm{h})$ \\
\hline 1000 & 10 & 150 & 2.5 \\
\hline
\end{tabular}

Table 2 Compositions of the electrolytes for MAO treatment prepared in this study

\begin{tabular}{lccc}
\hline Electrolyte solution & $\begin{array}{c}\text { Calcium glycerophosphate } \\
/ \mathrm{mmol} \mathrm{L}^{-1}\end{array}$ & $\begin{array}{c}\text { Magnesium acetate } \\
/ \mathrm{mmol} \mathrm{L}^{-1}\end{array}$ & $\begin{array}{c}\text { Total concentration of cations } \\
/ \mathrm{mmol} \mathrm{L}^{-1}\end{array}$ \\
\hline Solution 1 & 100 & 150 & 250 \\
Solution 2 & 50 & 75 & 125 \\
Solution 3 & 25 & 37.5 & 62.5 \\
Solution 4 & 12.5 & 18.75 & 31.25 \\
Solution 5 & 12.5 & 37.5 & 50 \\
Solution 6 & 12.5 & 75 & 87.5 \\
Solution 7 & 25 & 18.75 & 43.75 \\
Solution 8 & 50 & 18.75 & 68.75 \\
Solution 9 & 50 & 0 & 50 \\
Solution 10 & 75 & 18.75 & 93.75 \\
\hline
\end{tabular}




\section{Statistical analysis}

Data were first analyzed with one-way analysis of variance (ANOVA). When ANOVA suggested a significance difference $(p<0.05)$, post-hoc multiple comparison tests were carried out using Tukey tests.

\section{RESULTS}

\section{Effect of electrolyte concentration on MAO treatment}

During the MAO process with solutions 1 and 2, micro-arc discharges began to appear at many local sites and continued jumping around the entire surface of the specimen. In this period, the voltage quickly increased from zero to $400 \mathrm{~V}$ within 1 to 1.5 minutes. The voltage then fluctuated between 420 and $440 \mathrm{~V}$ until the end of the treatment. Six to 10 minutes after starting the treatment, the arcs became stronger while the number of the arcs decreased. Finally, a single and strong arc without migration existed for a relatively long period and caused a severe and localized oxidation of a certain area. On the other hand, in the case of the MAO treatment with solutions $3-10$, the micro-arc discharges began to appear at voltage of about $450 \mathrm{~V}$ around 1.5 to 2 minutes after starting. The voltage then quickly increased and reached a maximum value of $480 \mathrm{~V}$ within 2 to 3 minutes. After reaching the maximum voltage, the current density gradually decreased from 239 to $20 \mathrm{~A}$ $\mathrm{m}^{-2}$, and the micro-arc sparks became weak and fewer in number. In contrast to the cases with solutions 1 and 2 with a high concentration of electrolyte, the arcs were homogeneously distributed throughout the exposed area. However, the time required to completely oxidize the whole surface increased. In other words, when a high concentration of the electrolyte is used for MAO treatment, the required treatment time is short because of the strong micro-arcs. In addition, such a tendency was remarkable with the change in the concentration of magnesium acetate in the electrolyte.

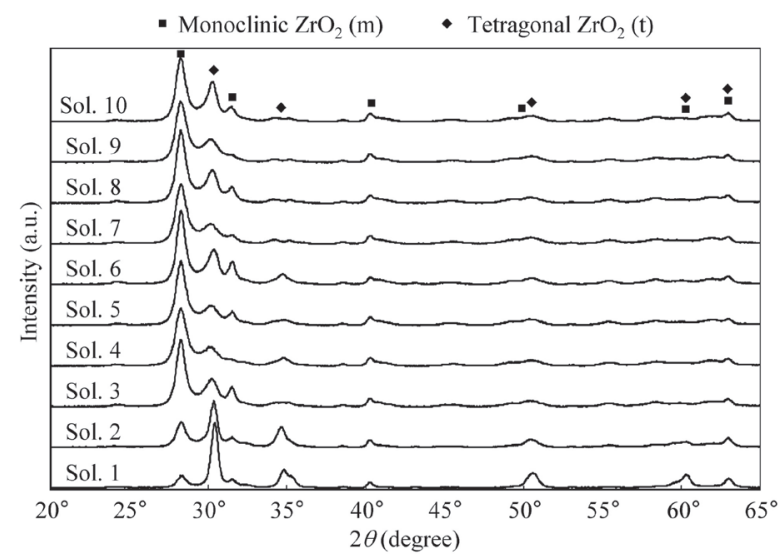

Fig. 1 X-ray diffraction pattern of the specimens after micro-arc oxidation with various electrolyte solutions.
Phase composition of the surface layer

Figure 1 shows the XRD patterns of MAO-treated specimens with different electrolyte concentrations. It shows that the oxide layers on the specimens were identified as $\mathrm{ZrO}_{2}$ with tetragonal ( $\mathrm{t}$ ) and monoclinic (m) crystal structures. The MAO-treated specimens in solutions 1 and 2, whose total cation concentrations were $250 \mathrm{mmol} \mathrm{L}^{-1}$ and $125 \mathrm{mmol} \mathrm{L}^{-1}$, respectively, showed stronger intensity of the (t) phases than the $(\mathrm{m})$ phases. On the other hand, in solutions 3 to 10 , in which the total concentrations of cations were less than $100 \mathrm{mmol} \mathrm{L}^{-1}$, the intensities of the $(\mathrm{m})$ phases were stronger than those of the (t) phases.
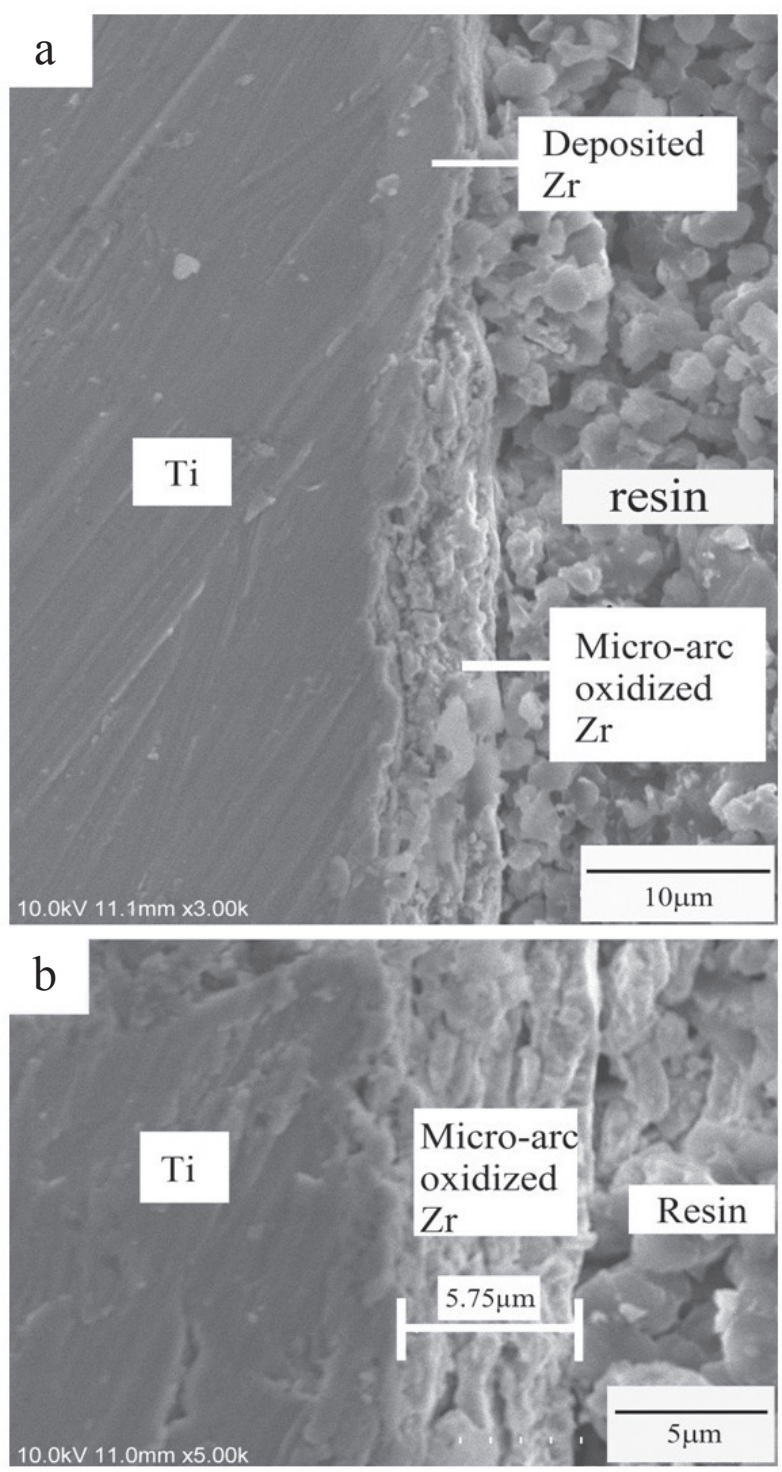

Fig. 2 Scanning electron micrographs of MAO-treated Ti with a sputter-deposited $\mathrm{Zr}$ layer. (a) Cross section of the area near the border between the oxidized and unoxidized area. (b) Higher magnification of the oxide layer. 

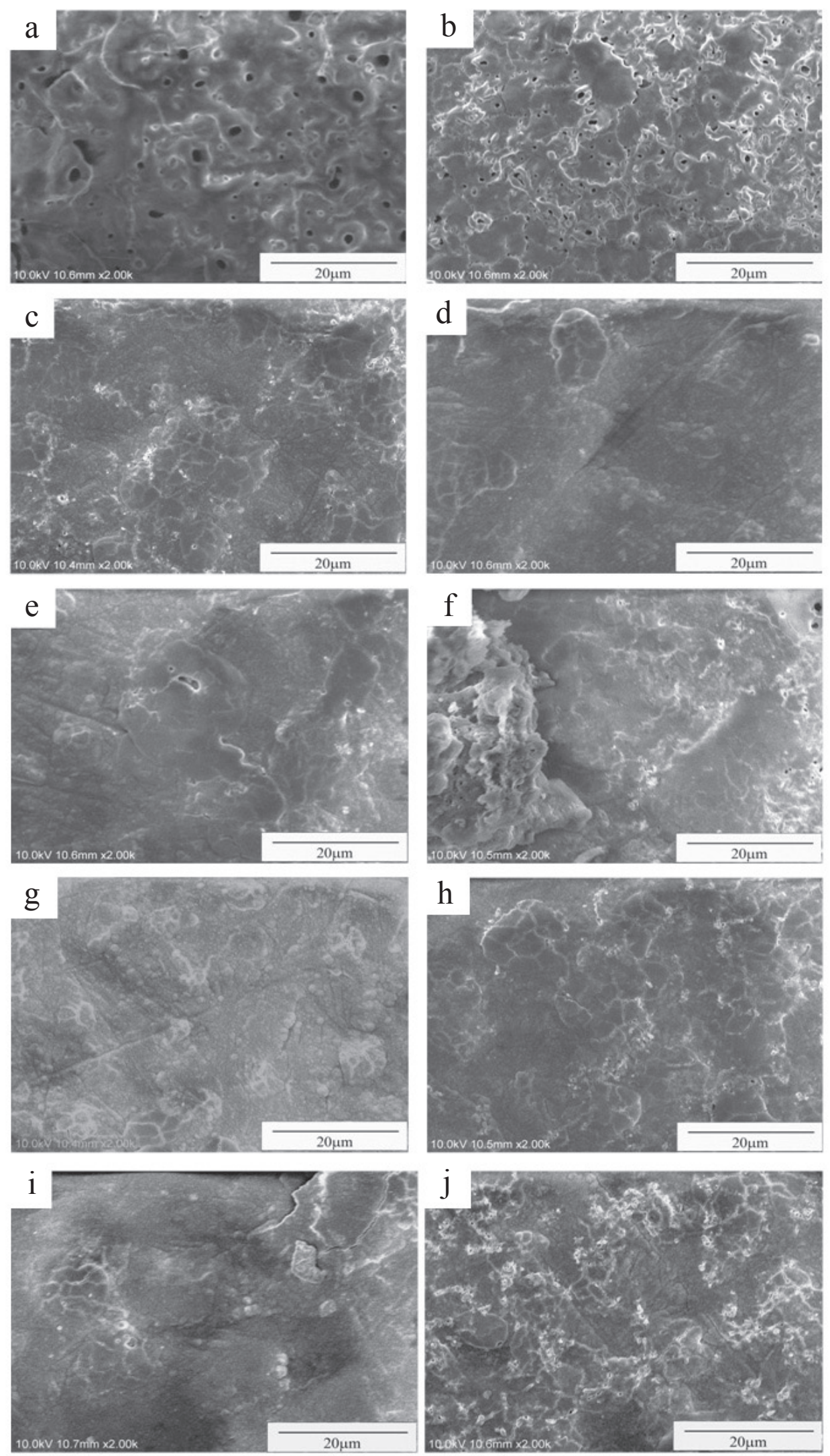

Fig. 3 Scanning electron micrographs of MAO-treated Ti with a sputter-deposited Zr layer with (a) solution 1, (b) solution 2, (c) solution 3, (d) solution 4, (e) solution 5, (f) solution 6, (g) solution 7, (h) solution 8, (i) solution 9, and (j) solution 10 . 
Surface morphology and composition

Typical SEM images of the cross sections of the specimen after MAO treatment in solution 4 were shown in Fig. 2. The top figure (a) was taken at the border between the MAO-treated area and the untreated area (which was not exposed to the electrolyte). Metal $\mathrm{Zr}$ layer was covered on Ti substrate at the untreated area. The thickness of the Zr layer was about $5 \mu \mathrm{m}$ and it was well accorded with the value from the prior calibration measurement. As shown in the figure, metal $\mathrm{Zr}$ layer was homogenously deposited and well integrated with the Ti substrate. On the other hand, MAO-treated area shows a rough layer instead of the metal $\mathrm{Zr}$ layer. As shown in the bottom figure (b), which is a high magnification of the MAO-treated area, the rough layer has a compilation structure and it was formed by the oxidation of the metal $\mathrm{Zr}$ layer during the treatment. The thickness of the oxide layer was $5.75 \mu \mathrm{m}$.

Figure 3 shows the surface of the oxidized layers. The morphologies varied with the concentration of electrolyte used for the MAO treatment. Large pores were formed on the surface when the concentrations of electrolyte were high (Fig. 3(a) and (b)). The mean pore sizes were 1-2 $\mu \mathrm{m}$ with solutions 1 and 2 , and it was larger than those formed with solutions $3,5,6,8$, and 10 (Fig. 3(c), (e), (f), (h), and (j)). This indicates that pores with significantly larger diameters were formed in the higher electrolyte concentration. Large pores may be originated from the strong micro-arcs with a solution of a higher electrolyte concentration. In this case, the resultant surface was heterogeneous because of the localized oxidation with strong micro-arcs. On the other hand, the micro-arcs appeared homogenously throughout the surface during the MAO process with lower electrolyte concentrations, resulting in fewer and smaller pores. In addition, with solution 4 or 7 , in which the concentration of magnesium acetate was the lowest, no pores were formed, and the resultant oxidized surfaces were relatively smooth (Fig. 3(d) and (g)). In other words, when the concentration of magnesium acetate

Table 3 Compositions of the oxide layer formed after MAO treatment with various electrolyte solutions measured by EDS

\begin{tabular}{|c|c|c|c|c|c|c|}
\hline \multirow{2}{*}{ Electrolyte solution } & \multicolumn{6}{|c|}{ Concentration (mol\%) } \\
\hline & $\mathrm{Zr}$ & $\mathrm{O}$ & $\mathrm{C}$ & $\mathrm{Ca}$ & $\mathrm{Mg}$ & $\mathrm{P}$ \\
\hline Solution 1 & 31.7 & 29.2 & 28.8 & 2.0 & 4.5 & 3.8 \\
\hline Solution 2 & 66.5 & 32.1 & 0.6 & 0.4 & 0.4 & - \\
\hline Solution 3 & 71.1 & 28.6 & - & 0.2 & 0.1 & - \\
\hline Solution 4 & 70.3 & 26.7 & 2.7 & 0.2 & 0.1 & - \\
\hline Solution 5 & 70.8 & 29.0 & - & - & 0.2 & - \\
\hline Solution 6 & 71.1 & 28.7 & - & - & 0.2 & - \\
\hline Solution 7 & 69.6 & 30.3 & - & 0.1 & - & - \\
\hline Solution 8 & 71.7 & 28.0 & - & 0.1 & 0.2 & - \\
\hline Solution 9 & 68.3 & 31.7 & - & - & - & - \\
\hline Solution 10 & 71.0 & 28.5 & - & 0.2 & 0.3 & - \\
\hline
\end{tabular}

a

b c d

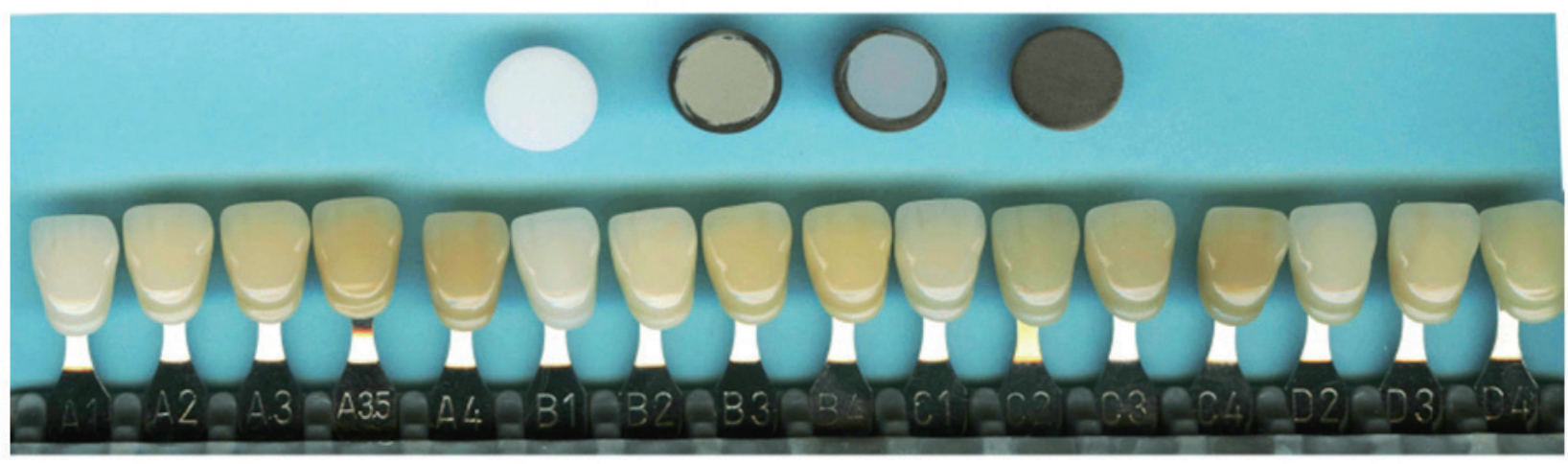

Fig. 4 Photograph of the specimens with tooth color: (a) pure zirconia, (b) MAO-treated Ti with sputter-deposited Zr in solution 4, (c) MAO-treated Ti without $\mathrm{Zr}$, and (d) pure Ti. 
increased, the frequency of the appearance of strong micro-arcs increased, and the resultant oxide layer was rougher with an increase in the number of pores, even though the calcium glycerophosphate concentration was the lowest (Fig. 3(f)). When the electrolyte solution contained only calcium glycerophosphate, the resultant oxide surface was fragile and showed many cracks, although no pores were formed on the surface (Fig. 3(i)).

EDS analyses were performed to determine the compositions of oxide layers formed with different electrolytes. The results are summarized in Table 3 . The surface layers were mainly composed of $\mathrm{Zr}$ and $\mathrm{O}$ for most specimens. It is interesting that $\mathrm{Ca}, \mathrm{Mg}$, and $\mathrm{P}$ were also detected from those formed with solutions 1 and 2. The MAO treatment with a high concentration of the electrolyte could produce a mixture of the metal oxide and additional elements, such as $\mathrm{Ca}, \mathrm{Mg}$, and $\mathrm{P}$, indicating that incorporation of the elements from the electrolyte into the oxide layer had occurred.

Color of the MAO-treated specimens

All specimens matched the colors of natural teeth

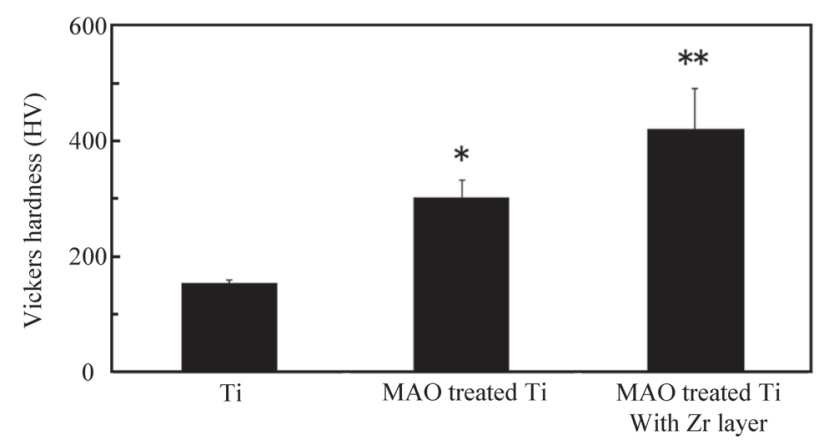

Fig. 5 Vickers hardness of the specimens' surface with and without MAO treatment in solution 4.

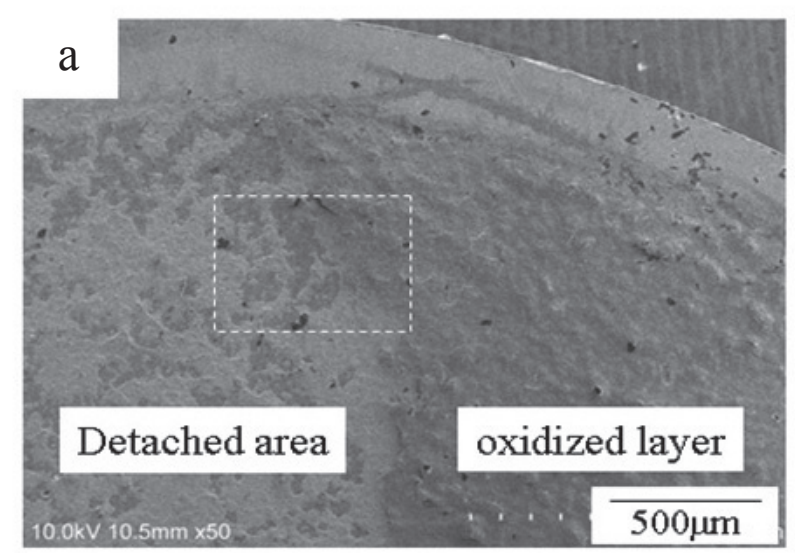

regardless of the type of electrolyte solution used for the MAO treatment; however, there were apparent differences in the colors of metal $\mathrm{Ti}$, and pure $\mathrm{ZrO}_{2}$. Figure 4(b) shows the specimen after MAO treatment in solution 4 (the most homogeneously coated). A pure $\mathrm{ZrO}_{2}$ (Fig. 4(a)), MAO-treated Ti without Zr layer (Fig. 4(c)), and an untreated Ti (Fig. 4(d) are also put as references. As shown in the figure, this specific color, favorable for dental implants, was achieved exclusively with the MAO treatment of the $\mathrm{Ti}$ specimen with sputter-deposited metal Zr.

\section{Hardness of the oxide surface}

Figure 5 shows the Vickers hardness of the specimens. The samples treated with solution 4 as the best condition were prepared for the hardness test because its coating layer was the most homogeneous without any pore. The Vickers hardness of the MAO-treated $\mathrm{Ti}$ with a $\mathrm{Zr}$ deposition layer was significantly larger than those of untreated $\mathrm{Ti}$ and MAO-treated $\mathrm{Ti}$ without $\mathrm{Zr}$. This clearly demonstrated that the surface of $\mathrm{Ti}$ could be significantly hardened by this technique because of the formation of the ceramic layer. It is notable that the mean hardness of this specimen was remarkably high $(425 \pm 75)$, which might have originated from the difference of the hardness of $\mathrm{ZrO}_{2}$ and titanium oxide $\left(\mathrm{TiO}_{2}\right)$.

\section{Bonding strength}

The apparent bonding strengths of the specimens were almost identical among specimens with different electrolyte solutions, and the average value was $11.2 \pm$ 4.5 MPa. Figure 6 shows SEM images of the Ti specimen with $\mathrm{Zr}$ deposition followed by MAO treatment in solution 4 after the adhesion detachment test. The same tendency was observed on the specimens with different solutions and it was obvious that the fractured surface was much rougher than the polished one before MAO treatment. From the fact that the color of the detached

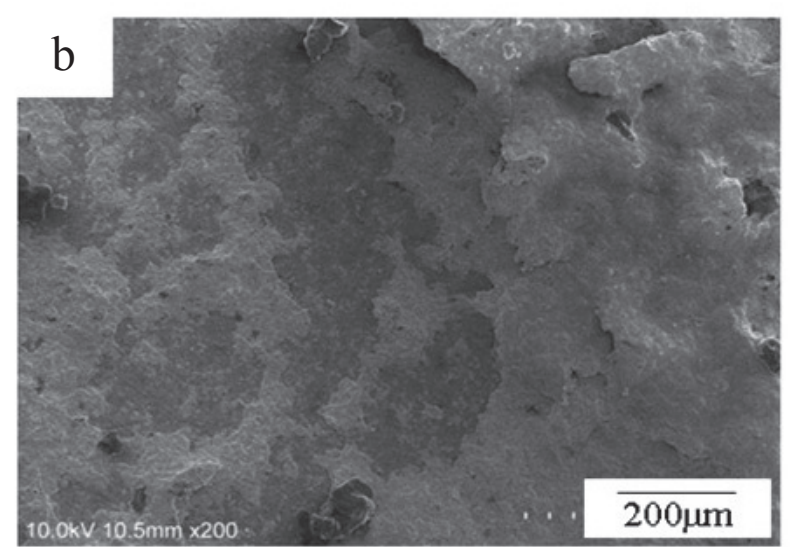

Fig. 6 Scanning electron micrographs of MAO-treated Ti with a sputter-deposited Zr layer with solution 4 after adhesion detachment test: (a) Overview and (b) higher magnification image of (a) presented in a dashed line square. 
area was still white, a considerable amount of oxide layer remained after the bonding test. Therefore, the fracture during debonding of the adhesive was not propagated at the oxide/substrate interface but inside the oxide layer, indicating that the oxide layer was firmly covered on the Ti substrate.

\section{DISCUSSION}

Zirconia ceramics is a widely studied material with good mechanical properties ${ }^{20)}$, reduced bacterial adhesion and colonization $^{21,22)}$, and reduced plaque accumulation ${ }^{23)}$. In addition, it has been shown to have good biocompatibility with connective tissue cells in vitro and excellent clinical performance ${ }^{24)}$. On the other hand, MAO is considered to be a useful method for the surface modification of Ti and $\mathrm{Zr}$ because it can produce porous and firmly adherent oxide layers on metal substrates, respectively, which can not only enhance the integration of the implants with bone but also improve their in vivo corrosion behavior 12,13,16,17). In this study, we applied the MAO technique to oxidize the sputter-deposited metal $\mathrm{Zr}$ layer on the $\mathrm{Ti}$ substrate. The objective was to produce a tightly adhered $\mathrm{ZrO}_{2}$ on the $\mathrm{Ti}$ substrate to achieve aesthetically favorable color without losing the excellent mechanical properties of Ti. We could successfully obtain hard tooth-colored $\mathrm{ZrO}_{2}$ layers on the Ti substrate.

The MAO technique can inevitably produce oxide layers on various metals and alloy surfaces with a porous structure. Although this porous structure has been proved to enhance the bioactivity and osteoblast response ${ }^{12-17)}$, which may be beneficial for osseointegration on the implants, the presence of the pores can be hazardous in terms of vulnerability to bacterial adhesion $^{25)}$ and subsequent risk of peri-implantitis, leading to implant failure, especially when the pores are exposed at the level of soft tissue attachment. We attempted to produce oxidized surfaces without pores and found that the pore formation can be successfully avoided by controlling the electrolyte composition and concentration. This is the first report that an oxidized surface without a porous structure can be produced by the MAO technique under proper conditions.

The color of the obtained oxide layer resembled that of natural teeth. This color would be a result of the combination of the thickness and crystalline structure of the oxide layer and was obtained only when the metal $\mathrm{Zr}$ was deposited on the Ti substrate. Two types of $\mathrm{ZrO}_{2}$ with different crystal phases, tetragonal (t) and monoclinic (m), were identified in XRD analyses. Reports indicate that the instantaneous temperature of the micro-arc discharge region rises up to $10^{3}-10^{6}{ }^{\circ} \mathrm{C}$ during the MAO process ${ }^{17)}$. When the solution with a high electrolyte concentration was used for the MAO treatment, bright and intense micro-arc discharges were generated, yielding higher temperature. This accounted for the formation of (t) phase, which is a high-temperature phase, rather than $(\mathrm{m})$ phase at a higher electrolyte concentration. On the other hand, the solutions with lower electrolyte concentrations (solutions 3 to 10) resulted in less intense micro-arc discharges, leading to the formation of $(\mathrm{m})$ phase. It is noteworthy that the inclusion of other elements, such as $\mathrm{Ca}, \mathrm{P}, \mathrm{Mg}$, and $\mathrm{C}$, in $\mathrm{ZrO}_{2}$ was remarkable when solutions 1 and 2 were used. It might be considered that the higher temperature made such elements easier to incorporate into the oxide layer, stabilizing the $(\mathrm{t})$ phase rather than the $(\mathrm{m})$ phase.

The strong adhesion of the coating layer on the substrate is required for clinical application. In this study, the adhesion-tension test revealed that the apparent bonding strengths were about $11 \mathrm{MPa}$. On the other hand, Japanese Industrial Standards for dental ceramic fused to metal restorative materials (JIS-T6516) defines the bonding strength between ceramic and metal layers more than $25 \mathrm{MPa}$. This value is not necessarily proper for the collar of a dental implant abutment, however, the resultant oxide layer in this study may have a room for improvement. The bonding strengths of oxide layers formed directly on $\mathrm{Ti}$ or $\mathrm{Zr}$ disks by the MAO technique have been reported ${ }^{15-17)}$ to be around 30 to 60 $\mathrm{MPa}$. It clearly demonstrates that the oxide layer formed by MAO treatment potentially has strong bonding with metal substrate. In this study, the fracture during the bonding test did not result in a substrate/oxide interface but occurred inside the oxide layer. In other word, the actual bonding strength is expected to be much higher because the oxide remained on the detached area. The discrepancy in the results of bonding test may be derived from the thick and brittle structure of the oxide layer. Thus, the bonding strength is expected to be improved if an oxide layer with little crack or defect can be formed by adjusting the treatment conditions. It would be necessary to test the integrity of the layer under various mechanical stresses exerted on dental implant abutments.

The technique in the present study has three main advantages over the direct sputter deposition of $\mathrm{ZrO}_{2}$ from a $\mathrm{ZrO}_{2}$ target. First, thick layers can be obtained with relatively shorter time and less energy, even though MAO treatment is necessary to obtain oxidized layers. Generally, the deposition rate of $\mathrm{Zr}$ from a metal target is about 10 times larger than that of $\mathrm{ZrO}_{2}$ from an oxide target ${ }^{9)}$. Secondly, aesthetically favorable layers with tooth color can be produced. The previous finding of Then et $a l .{ }^{9)}$ indicated that sputter-deposited $\mathrm{ZrO}_{2}$ from an oxide target did not result in tooth color. On the other hand, an oxide layer formed by this technique matched the color of natural teeth, whereas the colors could not be matched using the MAO treatment on pure Ti substrates. The third advantage is the selectability of the treatment area. The MAO treatment is based on an electrochemical reaction in an electrolyte solution; as a result, it is very easy to segregate an unnecessary area for oxidation by preventing electrolyte contact (e.g., coating with insulating paint).

In addition, this technique makes it possible to incorporate $\mathrm{Mg}, \mathrm{Ca}$, and $\mathrm{P}$ ions, which have been shown to enhance the bioactivity by the MAO treatment, into the surface layer. 


\section{CONCLUSION}

In this study, a novel coating technique of a thin ceramic layer on a $\mathrm{Ti}$ surface was developed. $\mathrm{A} \mathrm{ZrO}_{2}$ layer resembling the color of teeth with good mechanical properties was obtained by the combination of sputter deposition of metal $\mathrm{Zr}$ and a subsequent MAO treatment. The most homogeneous and dense coating layer was obtained when the specimen was MAO-treated with the electrolyte containing $12.5 \mathrm{mmol} \mathrm{L}^{-1}$ calcium glycerophosphate and $18.72 \mathrm{mmol} \mathrm{\textrm {L } ^ { - 1 }}$ magnesium acetate. From the results of surface characterizations, this technique has prospects for the development of novel dental materials with biocompatible, biosafe, and excellent aesthetic properties.

\section{REFERENCES}

1) Piconi C, Maccauro G. Zirconia as a ceramic biomaterial. Biomaterials 1999; 20: 1-25.

2) Qadri SB, Skelton EF, Lubitz P, Nguyen NV, Khan HR. Electron beam deposition of $\mathrm{ZrO}_{2}-\mathrm{ZnO}$ films. Thin Solid Films 1996; 290-291: 80-83.

3) Li Q, Zhong X, Hu J, Kang W. Preparation and corrosion resistance studies of zirconia coating on fluorinated AZ91D magnesium alloy. Prog Org Coat 2008; 63: 222-227.

4) Yeh SW, Hsieh TY, Mao SW, Gan D, Shen P. Zirconium and zirconia thin films prepared on $\mathrm{NaCl}$ by ion beam deposition. Mater Chem Phys 2007; 105: 127-135.

5) Carolan MF, Michaels JN. Chemical vapor deposition of yttria stabilized zirconia on porous supports. Solid State Ionics 1987; 25: 207-216.

6) Koski K, Holsa J, Juliet P. Properties of zirconium oxide thin films deposited by pulsed reactive magnetron sputtering. Surf Coat Technol 1999; 303: 120-121.

7) Ben Amor S, Rogier B, Baud G, Jacquet M, Nardin M. Characterization of zirconia films deposited by r.f. magnetron sputtering. Mater Sci Eng 1998; B57: 28-39.

8) George J. Preparation of thin films. New York: Marcel Dekker; 1992. p. 392.

9) Then IK, Mujahid M, Zhang B. Effect of processing on the structure and wear properties of sputtered zirconium oxide thin films. Surf Coat Technol 2005; 198: 104-109.

10) Yerokhin AL, Nie X, Leyland A, Matthews A, Dowey SJ. Plasma electrolysis for surface engineering. Surf Coat Technol 1999; 122: 73-93.

11) Voevodin AA, Yerokhin AL, Lyubimov VV, Donley MS,
Zabinski JS. Characterization of wear protective Al-Si-O coatings formed on Al-based alloys by micro-arc discharge treatment. Surf Coat Technol 1996; 86-87: 516-521.

12) Li LH, Kong YM, Kim HW, Kim YW, Kim HE, Heo SJ, Koak JY. Improved biological performance of Ti implants due to surface modification by micro-arc oxidation. Biomaterials 2004; 25: 2867-2875

13) Wei D, Zhou Y, Jia D, Wang Y. Effect of heat treatment on the structure and in vitro bioactivity of microarc-oxidized (MAO) titania coatings containing $\mathrm{Ca}$ and $\mathrm{P}$ ions. Surf Coat Technol 2007; 201: 8723-8729.

14) Han Y, Xu K. Photoexcited formation of bone apatite-like coatings on micro-arc oxidized titanium. J Biomed Mater Res 2004; 71A: 608-614.

15) Han $\mathrm{Y}$, Hong $\mathrm{SH}, \mathrm{Xu} \mathrm{K}$. Synthesis of nanocrystalline titania films by micro-arc oxidation. Mater Lett 2002; 56: 744-747.

16) Han Y, Yan Y, Lu C, Zhang Y, Xu K. Bioactivity and osteoblast response of the micro-arc oxidized zirconia films. J Biomed Mater Res 2008; 88A: 117-127.

17) Yan Y, Han Y. Structure and bioactivity of micro-arc oxidized zirconia films. Surf Coat Technol 2007; 201: 5692-5695.

18) Wirtz GP, Brown SD, Kriven WM. Ceramic coatings by anodic spark deposition. Mater Manuf Process 1991; 6: 87-115.

19) Tanaka $Y$, Kobayashi E, Hiromoto S, Asami K, Imai H, Hanawa T. Calcium phosphate formation on titanium by low-voltage electrolytic treatments. J Mater Sci Mater Med 2007; 18: 797-806.

20) Hulbert SF. The use of alumina and zirconia in surgical implants. In: Hench L, Wilson J eds. An introduction to bioceramics, advances series in ceramics. New York: World Scientific; 1993. p. 25-29.

21) Rimondini L, Cerroni L, Carrassi A, Torricelli P. Bacterial colonization of zirconia ceramic surfaces: An in vitro and in vivo study. Int J Oral Maxillofac Implants 2002; 6: 793-798.

22) Scarano A, Piattelli M, Caputi S, Favero GA, Piattelli A. Bacterial adhesion on commercially pure titanium and zirconium oxide disks: An in vivo human study. J Periodont 2004; 75: 292-296.

23) Gröbner-Schreiber B, Griepentrog M, Haustein I, Müller WD, Briedigkeit H, Göbel UB, Lange KP. Plaque formation on surface modified dental implants. An in vitro study. Clin Oral Implants Res 2001; 12: 543-551.

24) Bianchi AE, Bosetti M, Dolci Jr G, Sberna MT, Sanfilippo F, Cannas M. In vitro and in vivo follow-up of titanium transmucosal implants with a zirconia collar. J Appl Biomater Biomech 2004; 2: 143-150.

25) Wang $X$, Wang G, Liang J, Cheng J, Ma W, Zhao Y. Staphylococcus aureus adhesion to different implant surface coatings: An in vitro study. Surf Coat Technol 2009; 203: 3454-3458. 